\title{
VIGENCIA Y LÍMITES DEL LEGADO DE LA UNIDAD POPULAR EN EL CHILE DEL SIGLO XXI
}

Fanny Pollarolo Villa 


\section{FANNY POLLAROLO VILLA}

Médico psiquiatra de la Universidad de Chile. Ha sido profesora auxiliar de Psiquiatría de la Universidad de Chile (1966-1973) y profesora honoraria de la Pontificia Universidad Católica de Chile (1968-1970). Ejerció como diputada de la república entre 1994 y 2002. Actualmente integra el Equipo de Programas del Instituto Igualdad. 


\section{VIGENCIA Y LÍMITES DEL LEGADO DE LA UNIDAD POPULAR EN EL CHILE DEL SIGLO XXI}

El proceso de la Unidad Popular encabezado por el presidente Salvador Allende y su programa han marcado la historia de este país, dejando una huella indeleble en Chile y el mundo. Ese notable intento de desplegar al máximo el camino de la lucha social para plasmar una sociedad más justa, fue la culminación de un proceso político-social cuyas señales se encuentran ya a fines del siglo XIX, extendiéndose por todo el siglo XX hasta conquistar el gobierno el 4 de septiembre de 1970.

En el Chile de hoy, en los comienzos del siglo XXI, se viven momentos de gran complejidad.

A 47 años del golpe y a 30 de la transición, el nivel alcanzado por la crisis económica, política y social en el país se ha acompañado de un creciente malestar psicosocial que transcurría en aparente silencio, marcando la vida y la convivencia social de las mayorías. Se trata de un complejo fenómeno, en el que parecen integrarse una amplia gama de demandas y razones. Y si bien la mayor parte de ellas son de orden material, todas parecen teñidas de sentimientos profundos, en los que se encuentra la dignidad herida por la falta de respeto y el abuso, la ira por la discriminación y la desigualdad, la incertidumbre y la impotencia, y la profunda desconfianza y el rechazo hacia los políticos, las instituciones, los grandes empresarios y las elites de todo tipo.

En medio de ese clima, a fines de una década marcada por demandas sociales que no parecieron ser escuchadas, surgió el estallido y la revuelta del 18 de octubre de 2019. Un pueblo empoderado, con una juventud que se tomó la calle, grupos que ejercieron distintos grados de violencia. Un feminismo organizado y movilizado, que impulsó la mayor marcha de la historia. Una crisis que exigió al nivel político encontrar alguna forma de dar respuesta a quienes, exigiendo ser escuchados, habían llegado a provocar niveles críticos de ingobernabilidad.

Encabezada por las nuevas generaciones, su fuerza alcanzó tal magnitud que logró vencer la inercia política que se vivía en el país, generando nuevas condiciones sociales y políticas que posibilitaron abrir un camino de salida a la grave crisis existente. Se movilizan entonces grandes esperanzas de cambios radicales, que hoy la inmensa mayoría (sectores populares y también capas medias) reconoce como indispensables y considera exigibles ante quienes tienen la obligación de darles respuesta. Aprobado por amplísima mayoría, se ha iniciado el camino del proceso constituyente que formulará una Nueva Constitución para el país. 
Chile enfrenta, entonces, un notable camino que exige sea asumido no solo con gran esperanza, sino también con la exigencia de caminarlo realizando profundas reflexiones, que permitan efectuar la tarea propia del constituyente. Al mismo tiempo, resulta necesario revisar las debilidades y problemas que tocan aspectos muy centrales para una democracia y que han sido gravemente dañados por el neoliberalismo, aún instalado en Chile. Dichos aspectos, requieren ser corregidos y recuperados para que exista coherencia con la democracia ampliamente participativa que hoy se exige y que deberá ser construida en la nueva carta ciudadana.

Es para estas reflexiones donde el legado de la Unidad Popular parece estar plenamente vigente, en la medida en que permite recuperar la ética social y enriquecerla con los valores de la cultura actual; al mismo tiempo que facilita reconstruir al sujeto político social que formó parte de ese periodo histórico y que resulta indispensable para el éxito de un futuro proyecto democratizador.

Recoger como un importante legado todo aquello que está a la base del entusiasmo y la mística de esos históricos tres años, en los que se movilizo y estimuló la creación y la solidaridad, es también dar continuidad histórica a un eje valórico que formó parte sustantiva de la cultura política y social chilena, y que en este siglo XXI se debe recuperar.

El proceso constituyente ya aprobado, que será electo en su totalidad y paritario, deberá recoger las demandas y el sentido ciudadano expresado con fuerza desde la calle, definiendo la nueva Carta Fundamental desde procedimientos inéditos y más democráticos. Es así entonces que, en el Chile actual, que ha vuelto a ser un tiempo de profundos cambios, recogemos el legado de Allende y la Unidad Popular destacando aquellos aspectos que parecieran necesitar más profunda e intensa reflexión.

$\mathrm{Al}$ enfrentar este nuevo momento de cambios y trasformaciones, el legado de la Unidad Popular entrega elementos que, desplegados con mucha fuerza en el proceso y en la figura y vida política de Allende, parecen alcanzar hoy día una especial vigencia.

\section{LA VIGENCIA DEL LEGADO}

Dos son los aspectos que, referidos al campo de lo social y lo político, parecen ser especialmente valiosos de destacar, por cuanto tuvieron un destacado papel en la lucha del movimiento popular y luego en el gobierno del presidente Allende, habiendo sido también muy centrales a lo largo de la historia de la democracia chilena. Se trata, además, de aspectos que, respondiendo a necesidades de la lógica mercantil del modelo neoliberal instalado, sufrieron un daño que se ha prolongado hasta el presente. 
Uno de ellos se refiere a los aspectos éticos de la vida en sociedad, es decir, a los valores y sentidos de las normas que guían la conducta social. El otro corresponde al histórico fenómeno chileno del sujeto político-social, esencial en el proceso de la Unidad Popular y prácticamente ausente hoy. En ambos casos, resulta especialmente significativo el legado de quienes desarrollaron la gesta encabezada por Allende, en la que culminó una larga historia patria que maravilló al mundo y aún se la recuerda con orgullo y con nostalgia.

Recoger esta memoria puede ser un gran aporte para la necesaria reconstrucción de valores y prácticas perdidas, así como también un gran impulso para encauzar la nueva mística que requiere el proceso de cambio y construcción que este Chile del siglo XXI, enfrentado a grandes desafíos y nuevas oportunidades, se encuentra exigido de abordar.

\section{EL DETERIORO DE LA MORAL SOCIAL}

Uno de los aspectos se refiere a la moral social, que en Chile constituía un claro deber ser y cuyas normas, antes que legales, respondían a una clara visión ética respecto a lo justo y lo injusto en el comportamiento en sociedad. En ella, más que la letra de la ley, siempre fue el sentimiento de culpa o vergüenza el indicador de un reproche ético capaz de frenar conductas que, respondiendo a objetivos deseables, contradecían la moral social. "Pobre pero honrado", fue siempre una expresión muy sentida en el mundo popular. Igualmente satisfactorio se sentía el afirmar que las altas autoridades del país se retiraban del cargo con las mismas posesiones materiales con las que habían llegado a él. La educación pública y la universidad estatal abrieron la mirada hacia lo colectivo incorporando el espíritu de responsabilidad social. Unido a todo eso, la historia de las luchas sociales iniciadas a fines del siglo XIX y comienzos del XX, fuertemente marcadas con los valores de la justicia, la igualdad y la solidaridad, tiñeron la cultura y la moral de este país.

La fuerza de estos valores fue probablemente aquello que hizo posible enfrentar durante 17 años a una dictadura que sustentó su poder en la instalación del terror y la barbarie. Ante la necesidad de defender la vida y recuperar la perdida democracia, una historia política y social sustentada en los valores de justicia y solidaridad fue lo que, en aquellos duros años, orientó la conducta valerosa de hombres y mujeres, muchos de ellos dispuestos a perder la propia vida.

El vaciamiento ético del comportamiento público ocurrió posteriormente.

La condición de democracia amarrada constitucionalmente, que llevaba en su interior una lógica económica que desconocía la moral social que había guiado por décadas la conducta en sociedad, fue generando un profundo y empobrecedor cambio cultural. 
Se trataba de una nueva economía, apoyada en su elaboración por la derecha chilena, que supo encajonarla en la Constitución elaborada por Jaime Guzmán y aprobada bajo la dictadura. Su objetivo se dirigía a asegurar la denominada "democracia protegida", de la cual formaba parte un nuevo ideario cultural requerido por el sistema y basado en la aparición de un nuevo sujeto, radicalmente distante de lo social, como había sido el propio de la democracia chilena antes de la dictadura. Se trataba de sujetos que expresaban la lógica de dejar de ser ciudadanos para ser solo consumidores, individualistas y competitivos, centrados en ellos mismos, ausentes de toda acción política y aspiración o confianza en un cambio social mayor. Esto fue incluso confirmado por autoridades de gobierno, para quienes no existían ciudadanos, sino consumidores.

La ausencia de un debate sobre un cambio cultural que se apreciaba desprovisto de toda ética, constituye la debilidad de los gobiernos de la Concertación más difícil de comprender. Las diferencias al interior de ella existían, escritos de debate y publicaciones eruditas dejaban ver los vacíos de sentido que empobrecían un proceso que había tenido su origen en un tiempo de entrega y compromiso. Una "modernidad sin alma" la llamaron en 1998 los "autoflagelantes". Estudiosos criticaron una globalización y una apertura que solo miraba el desarrollo tecnológico, sin ver el subdesarrollo social y político que se generaba. El Programa de las Naciones Unidas para el Desarrollo (PNuD) realizó un desnudo diagnóstico sobre un crecimiento que, limitado a la economía, resultaba incapaz de generar sentimientos de pertenencia y cohesión social. Valiosos textos y publicaciones que apuntaban a los riesgos de la lógica de mercado y de la visión thatcheriana sobre aceptar solo a los individuos, negando la realidad de las comunidades.

Personalidades y académicos, algunos ligados al pensamiento crítico de los cristianos, dejaron estampados el grave vacío ético que constituye la injusticia de una economía que concentra en pocas manos el bienestar material y el éxito, divide la sociedad en triunfadores y perdedores, y transforma la apariencia y la riqueza en las señales de prestigio y valor requerido en las competitivas relaciones humanas de la nueva modernidad.

Nació así, en la primera década de los gobiernos democráticos, un malestar ciudadano que cursó por años, agravándose y complejizándose cada vez más, hasta culminar en los recientes hechos del 18 de octubre recién pasado. Los vacíos valóricos antes descritos forman, sin duda, parte de esa coyuntura.

Un estudio del año 2005 aborda los fenómenos subjetivos que experimentaban sectores populares y medios de la sociedad, apareciendo en el registro graves sentimientos de exclusión social y ausencia de oportunidades, junto a frustraciones muy ondas referidas a la dignidad y el reconocimiento personal. Un marco muy amplio de emociones que, si bien en ese momento solo se sufrían, luego llenaron las 
consignas y lienzos de las numerosas protestas sectoriales que fueron apareciendo en la última década. La moral y la ética reaparecía en las calles, para luego ser parte del ideario expresado en los rayados y pancartas del sorprendente estallido del 18 de octubre de 2019, con el que se inició una revuelta capaz de poner en marcha una nueva historia.

\section{LA ÉTICA EN ALLENDE Y LA UNIDAD POPULAR}

El legado de Allende, y del proceso que encabezó, muestra con mucha claridad el valor otorgado al sentido ético de la vida en sociedad.

Si entendemos la ética como aquel principio que demanda que las normas morales sean sometidas a la reflexión valórica, es decir, que sean evaluadas en la perspectiva de lo bueno y justo versus lo malo e injusto, podemos afirmar que aquello fue siempre el marco que orientó al proyecto de la Unidad Popular y al actuar político de Salvador Allende.

Es en la figura de Allende, expresada en sus discursos y mensajes, así como en los recuerdos de tantas y tantos que lo conocieron y acompañaron, donde mejor se documenta y refleja la carga valórica del proyecto que él encabezaba. Es así que, a pesar de la extrema animadversión que muchos experimentaron y aún experimentan en su contra, nadie puede desconocer que la ética de la justicia, la solidaridad y la dignidad fueron parte sustantiva de su vida política y del proyecto que siempre impulsó.

Sus mensajes y discursos se experimentan siempre llenos de un sentido pleno de humanidad y de eticidad.

Así ocurre con el discurso formulado por Allende la noche del triunfo. Un pequeño trozo, que ha sido recogido y reiterado muchas veces, es el que se refiere al ingreso del pueblo a La Moneda, acompañándolo a asumir el mando e iniciar el proceso de la triunfante Unidad Popular. Se trata de una frase cargada de simbolismo, en tanto en ella se condensa el sentido de la tarea y la fuerza que representa el reconocimiento de ese sujeto social popular, ignorado hasta entonces en la historia de Chile. En ese gesto de su discurso la noche del triunfo, Allende rechaza esa discriminación, reconociendo en el pueblo a un actor del desarrollo, asumiéndolo como un sujeto digno de ocupar responsabilidades y ser parte de los equipos de decisión en la nueva democracia que comenzaba a construirse.

No cabe duda, entonces, que los valiosos aspectos referidos a la moral social y a una ética solidaria que enmarcaron el programa de la Unidad Popular pueden ser recogidos como ricos materiales para las necesarias reflexiones del momento que vive actualmente Chile. 
Era una moral llena de sentido la que guiaba al proyecto de la Unidad Popular. $\mathrm{Al}$ otorgar plena dignidad a quienes vivieron siempre discriminados, haciendo que un elemento central del ideario fuera considerar al pueblo un actor protagónico del cambio, convirtió ese tiempo en una experiencia desbordante de alegría y entusiasmo, una exaltación que algunos han descrito como una fiesta. Un tiempo en el que se trabajó al extremo, sintiendo el cansancio de una tarea agotadora junto con el goce del compartir, crear y hacer historia. Nada parecía imposible, porque todo se realizaba en conjunto, bajo la guía de un proyecto que tenía un profundo sentido colectivo. Y donde también la tarea era potenciada con el estudio y el aprendizaje. Porque existió la Editorial Quimantú, y con ella fue posible que la cultura, los libros y las artes llegaran también a los hombres y mujeres que habían vivido siempre postergados e ignorados.

Nadie era olvidado. Ni la infancia, ni la juventud, ni la vejez. Todos y todas eran reconocidos como actores sociales y eran llamados a participar. También las mujeres, aunque el pensamiento feminista, ya desarrollado en su Segunda Ola en Europa, no alcanzó a estar presente durante la Unidad Popular. En ello trabajaba Julieta Kirkwood al interior de la Universidad de Chile, pero su profundo y fuertemente crítico libro no alcanzó a ser conocido por Allende y los integrantes del proceso.

Todos estos valores estuvieron siempre presentes en sus discursos. Al dirigirse al país el 4 de septiembre de 1970, desde el balcón de la Federación de Estudiantes de la Universidad de Chile, Allende hace un llamado a todos y todas en sus organizaciones:

"A los comités de empresas, de fábricas, de hospitales, en las juntas de vecinos, en los barrios y en las poblaciones proletarias, para que vayan estudiando los problemas y las soluciones porque presurosamente tendremos que poner en marcha el país. Yo tengo fe, profunda fe en la honradez, en la conducta heroica de cada hombre y cada mujer que hizo posible esta victoria".

Es así como el otro, el humillado, el ignorado, fue por primera vez valorado por las altas autoridades de la nación, reconocido en su capacidad de construir, tan digno como todo el resto de los ciudadanos y ciudadanas de este país. Se les reconoció organizados, responsables de tareas y servicios a la comunidad, conscientes al formar parte de un proceso de tanta trascendencia. Eran llamados a un trabajo que sabían indispensable, en el que deberían colocar el esfuerzo personal y la entrega necesaria. Al mismo tiempo que se sentían exigidos para una tarea nueva y difícil, experimentaban el valor y la fuerza que el propio presidente les entregaba al confiar en ellos y hacérselos saber, dejando de ser entonces los postergados, los jamás escuchados. Un gesto moral de un líder que otorgó valor y demandó trabajo 
al mismo tiempo que entregó su confianza y su respaldo, permitiendo que ese colectivo humano que lo acompañaba dejara de ser considerado uno de personas de segunda clase, porque se les reconocía portadores de ciudadanía plena, tan dignos y capaces como todo el resto.

En el cierre final de su intervención, el presidente Allende vuelve a entregar un mensaje que evidencia el profundo vínculo, cargado de valor social, que lo enlaza con quienes celebran el triunfo y lo escuchan, cuando dice:

"A la lealtad de ustedes responderé con la lealtad de un gobernante del pueblo, con la lealtad del compañero presidente".

Se percibía claramente que esa emocionada declaración, cargada de un compromiso moral con quienes iniciaban con él ese proyecto histórico, no constituía una frase vacía. Así lo demostró tres años más tarde.

No resulta entonces sorprendente que en el proceso de la Unidad Popular estén presentes quienes, pertenecientes al mundo cristiano, habían hecho una opción por los pobres. La creación del Movimiento de Cristianos por el Socialismo significó la incorporación de numerosos sacerdotes, religiosos y religiosas, pastores y laicos, en todas las áreas de trabajo del proceso que encabezaba Allende, en el cual se sentían siguiendo los pasos de Jesucristo, junto a los pobres, en las luchas y esperanzas de los trabajadores.

En esa rica experiencia, que marcó a generaciones, se compartía una moral social enmarcada por un humanismo que unía a creyentes y agnósticos, haciendo posible una práctica solidaria que, sustentada en principios de justicia e igualdad, evidenciaba un radical respeto a la dignidad de cada uno.

\section{EL SUJETO POLÍTICO-SOCIAL. SU DESAPARICIÓN Y LA NECESIDAD DEL REENCUENTRO}

La estrecha alianza político social que marcó la historia chilena del siglo XX hasta la dictadura, constituyéndose en un eje histórico ampliamente desplegado en el proceso de la Unidad Popular, es donde se aprecia un segundo y grave déficit de la democracia desarrollada en la transición.

El distanciamiento del poder político con la ciudadanía, en especial con el mundo popular, y el debilitamiento de sus organizaciones, fueron parte del modelo individualista y pasivo que, como ya se ha dicho, consistía en un consumidor que debía confiar en el "chorreo" de quienes concentraban la riqueza, perfil humano requerido por el enfoque mercantil del modelo heredado, cuya lógica erradicaba la concepción del sujeto social. 
El fenómeno de la parlamentarización de la política, evidenciado desde el inicio de la transición, determinó que las fuerzas políticas comprometidas con la plena democracia, recluidas ahora en un ámbito constitucionalmente amarrado, resultaran incapaces de provocar cambios de fondo a un modelo que se había preparado para que ello no ocurriera.

Enclaustrados en el Parlamento, los partidos democráticos no establecieron lazos con las movilizaciones sociales que comenzaban a expresar sus demandas, pareciendo lejanos a concebir la construcción de una fuerza social que, constituida en mayoría ciudadana y en conjunto con estructuras políticas democráticas, hiciera posible los cambios que desde un Parlamento solitario y constitucionalmente frenado sería imposible lograr.

La lejanía y distancia de los partidos fue aumentando. Ignorantes de los sentimientos de ira y frustración, de la humillación ante la desigualdad creciente y los abusos cada vez más escandalosos, no veían que la desconfianza de la ciudadanía iba en aumento al percibirlos como una elite poseedora del bienestar, abusiva y discriminadora.

Las críticas políticas al interior del bloque gobernante de la Concertación fueron numerosas, pero públicamente casi desconocidas, sin alcanzar mayor desarrollo ni ninguna fuerza capaz de constituirse en factor de cambio.

Nada parecido a una estrategia política orientada a mediano o largo plazo fue planteada y todo siguió, para una centroizquierda la mayor parte del tiempo gobernante, como una tarea a resolver solo desde el Parlamento. Y la situación, aunque para muchos llegó a considerarse de nivel crítico, como por ejemplo en el gobierno de la presidenta Bachelet, apareció siempre como algo casi imposible de resolver.

Y es a partir de la revuelta social del 18 de octubre y la evidencia de una distancia entre la ciudadanía y la política que había llegado a constituirse en un franco e irritado rechazo, convirtiéndose en una problemática altamente sensible para un periodo de cambios amplios y profundos como los que el Chile de hoy debe enfrentar.

Frente a la indispensable pero difícil tarea de reconstruir el vínculo entre la política partidaria y el actor social, el legado dejado por Allende y la Unidad Popular pueden constituir un enriquecedor apoyo para las indispensables reflexiones que debemos realizar.

\section{ENSEÑANZAS DEL SUJETO POLÍTICO-SOCIAL DE LA UNIDAD POPULAR}

Es el sujeto político-social la más potente lección, el mayor legado, de quien fue llamado cariñosamente "el compañero presidente" Una fuerza que no solo se 
mostró en la campaña y en las urnas, sino también en cada uno de los mil días que duró la odisea de la Unidad Popular.

Ello fue lo que marcó ese pedazo de historia, convirtiéndolo en un accionar épico de hombres y mujeres, adultos y niños que sorprendieron - y aún sorprende al que la conoce por primera vez- por la entrega alegre y esperanzadora de la energía, el tiempo e incluso la propia vida. A pesar de las enormes dificultades que desde el comienzo debieron enfrentar Allende y el proceso, fue gracias al esfuerzo permanente de esa mayoría, lograda ya en las elecciones municipales en el segundo año de gobierno, que se tuvo la capacidad de hacer funcionar el país venciendo a quienes buscaban paralizarlo, al mismo tiempo que avanzar en los grandes cambios comprometidos en el programa.

El sujeto político-social es, en realidad, un legado de la izquierda del siglo $\mathrm{XX}$, que concebía la actividad política como una tarea realizada necesariamente desde los partidos, pero unida a un fuerte y decisivo anclaje social. Dirigentes, tanto del ámbito político como social, mantenían una estrecha relación con las organizaciones sociales y el mundo popular, sustentada en un vínculo que permitía una responsabilidad compartida de los procesos que se impulsaban y los caminos por los que se transitaba.

En ello, Allende y su historia de más de 50 años de trabajo político como ministro de salud, candidato presidencial y senador, constituyen el más importante legado a recoger en tiempos como hoy, marcados por la enorme debilidad y distanciamiento de la sociedad y los políticos producida a lo largo de los 30 años de transición a la democracia.

Quizá, la mayor lección política del legado de Allende fue esa coherencia de vida que le hizo mantener, sin ninguna trasgresión, su tendencia a contactarse con el pueblo y ser un político que combinaba memorables discursos en el Parlamento con reuniones con pobladores, mujeres dueñas de casa, trabajadores en huelga, campañas que significaban permanentes recorridos callejeros en pueblos y ciudades del país. En sus discursos siempre se apreció la extraordinaria conexión entre quien expresaba las ideas y la ciudadanía hacia quien ellas iban dirigidas. Procesos intersubjetivos que permitían compartir sentidos movilizadores de confianza hacia la persona del dirigente, al mismo tiempo que esperanza respecto a ideales que se sentían realizables. En Allende, la Unidad Popular y el proceso que se vivía entrelazaban el pasado con el futuro luminoso que se proyectaba, otorgando un profundo sentido histórico a la etapa que se sentían construyendo.

Las reflexiones que dicha tarea exige llevar a cabo con urgencia, encuentran ricos elementos evidenciados, muy especialmente, en el ejercicio del liderazgo allendista y también en las respuestas de las mujeres y hombres que lo acompañaban. Muchas son las enseñanzas que entregan los discursos de Allende, las que pueden constituir un 
gran aporte para aquellos políticos que, aunque sinceramente comprometidos contra el neoliberalismo, fueron distanciándose de la ciudadanía, también en el lenguaje.

Los discursos de Allende, sus palabras, tenían un hondo efecto en sus seguidores. Lo escuchaban en los mítines, las convocatorias en las plazas de pueblos y ciudades. Lo leían y lo oían a través de las radios. Los conmovía y los entusiasmaba. Porque Allende sabía hablar integrando la razón con las emociones. Son discursos cargados de entusiasmo y de pasión, eran los de un dirigente convencido del valor de la tarea que lleva mucho tiempo intentando realizar y que continuará hasta lograr su cumplimiento.

Aunque su estilo de tribuno y el tono de voz, propio de épocas anteriores, no resultaría aplicable en la actualidad, Allende sabía integrar y compartir las ideas que, junto con ser convincentes y bien fundadas, se ofrecían llenas del entusiasmo y la emoción que otorga un construir con sentido.

La conciencia de lo épico de la tarea estuvo siempre presente en Allende, quien supo transmitirlo en discursos que renovaban energía y potenciaban el entusiasmo de quienes lo acompañaban en una tarea que se sentía histórica. Fueron parte significativa de esa especie de mística creadora que tenía el proceso. Con ellos crecía el entusiasmo y se acrecentaba la voluntad, acompañando la alegría de sentirse multitud y saberse parte de algo grandioso.

Esta épica que acompañó a Allende durante la década y media que duró su campaña - y que hizo eclosión en el triunfo del 4 de septiembre y durante cada uno de los mil días de la Unidad Popular- mostró una masa popular que se había desarrollado. Ya no era solo producto de la presencia de un gran líder. Era un flujo de pensamiento impregnado de valores que abría un camino para dar respuesta a necesidades económicas y sociales siempre postergadas. Ello era posible gracias al desarrollo del actor político, que era también social, y del sujeto social poseedor ya de una visión política que le permitía jugar su papel histórico. Una amalgama que hacía posible abrirse a lo nuevo para construirlo, colectivamente, desde los distintos niveles del poder en la sociedad.

Un aspecto a destacar en los contenidos de los discursos y otras comunicaciones de Allende, se refiere a la permanente presencia en ellos de quienes, proviniendo del pueblo postergado, se habían convertido en constructores de una gran tarea. Todos y todas, viejos, jóvenes y niños, pobladores, mineros, trabajadores del campo y la ciudad, los olvidados de siempre, aparecían recordados como parte sustantiva de lo extraordinario que se emprendía. Por eso en sus intervenciones Allende no dejó de mencionarlos. Parecía que los llevara consigo. Así les habló:

"a los que están en la pampa y en la estepa, a los que me escuchan desde el litoral, para los que laboran en la precordillera, para la dueña de casa y el catedrático 
universitario, para el joven estudiante, el pequeño comerciante y el industrial, para todos ellos"

Eran cambios profundos los buscados, revolucionarios en sus objetivos, aunque no en sus métodos. Para alcanzarlos se requeriría mucha entrega junto a la emoción y la épica que también debía acompañarlos.

"Vamos a trabajar más, vamos a producir más, Y este triunfo debemos tributarlo en homenaje a los que cayeron en las luchas sociales y regaron con su sangre la fértil semilla de la revolución chilena que vamos a realizar"

"Acepto este triunfo que nada tiene de personal. Le debo este triunfo al pueblo de Chile, que entrará conmigo a La Moneda el 4 de noviembre".

Es así que lo fundamental, aquello en donde radica el principal legado de la Unidad Popular, parece ser el nexo, la conexión humana que se estableció siempre con ese mundo popular que constituyó su base y su fuerza. Aunque fue Allende el fundamental exponente y principal impulsor de un trato propio del compañerismo y la horizontalidad, pronto todo ello formó parte del clima y las relaciones que todos y todas compartían, por cuanto eran los lazos que surgían del saber y sentir que del marchar juntos dependía el éxito del camino trazado.

\section{LOS LÍMITES DEL LEGADO}

No resulta fácil referirse a los límites del legado de Allende y del proceso del que fue líder. No lo es porque prima aquello que se asemeja a una trágica ubicación temporal, a un desajuste con la situación que se vivía en el mundo al momento del triunfo.

La segunda derrota presidencial en 1958, por solo 30 mil votos, pudo haber sido el triunfo que llevara a la presidencia a un Allende que había formado parte de ese Frente Popular liderado por el Partido Radical, proceso en el que habían llegado al gobierno levantando los grandes valores de justicia social venidos la década del veinte.

En esa segunda candidatura ya era evidente el liderazgo popular de Allende, y su estrategia estaba igualmente basada en la alianza amplia de las fuerzas de izquierda por el cambio, con el papel decisivo del pueblo para llegar al gobierno y abrir cauce a una democracia mucho más amplia.

Solo podemos imaginar lo ocurrido si ese triunfo hubiera llegado en esa segunda candidatura de Allende, sin la revolución cubana ni el eurocomunismo, sin el peso 
del fenómeno guerrillero de los sesenta y, sobre todo, sin que estuviera en marcha la construcción del nuevo modelo económico y político del que la derecha chilena y sus intelectuales eran parte. El modelo neoliberal que, posteriormente, estuvo escrito y listo para ser instalado luego de que se hubiera impedido la asunción al poder de Allende, o bien mediante el quiebre de la institucionalidad republicana y democrática con la instalación de la dictadura, como ocurrió al cabo de tres años.

Todo confluyó en un entretejido muy complejo y lleno de contradicciones.

Es posible que, en un determinado momento histórico, la dinámica de los procesos en marcha haga muy difícil una justa evaluación de las fuerzas. Podría ser también que, en 1970, la dinámica alcanzada por ese histórico proceso de cambio en Chile no permitía detener lo avanzado, aunque ya estuviera apoyado por una clara mayoría ciudadana. Por otra parte, tanto los fenómenos guerrilleros existente entonces en Latinoamérica, como los procesos democratizadores que se realizaban en Europa, especialmente las señales del eurocomunismo - aunque siendo evaluados desde muy diferentes miradas-, reforzaban y complejizaban la visión política e ideológica de la propuesta allendista, convirtiéndola en extraordinariamente peligrosa para sus opositores del Norte.

Muchas son las preguntas que se hacen y que se seguirán haciendo para apreciar con mayor claridad los límites del legado de Allende y la Unidad Popular, y procesar las lecciones que pueden ser extraídas desde esos límites para el Chile del siglo XXI. Quizá lo único posible de formular se refiera a las profundas diferencias entre el tiempo en que se llevó a cabo el proyecto popular de Allende y los procesos que ocurren en la actualidad en Chile, donde una sorprendente mayoría ciudadana empuja y fuerza la realización de profundos cambio, políticos y sociales en el país. Se trata, sin duda, de un mundo marcadamente distinto del vivido por Allende y la Unidad Popular.

En la actualidad, todo pareciera indicar el anuncio de cambios epocales, tal vez civilizatorios. Las crisis nacionales forman parte de crisis globales y, por tanto, son compartidas a nivel mundial, lo cual marca profundas diferencias con la época de guerra fría en el que se llevó a cabo el proceso allendista.

Nos encontramos en un siglo XXI que, a diferencia del anterior, empuja al pensar sistémico a mirar la economía integrándola al bienestar y el cuidado de la vida y la naturaleza. Un mundo que busca el cumplimiento efectivo de los derechos humanos de todas y todos. Un mundo que avanza hacia una visión feminista y humana de la vida. Una época en la cual a los valores permanentes de la justicia y la igualdad, se añaden ahora los valores de la convivencia, la dignidad y el reconocimiento del otro. Que define una concepción de la igualdad que respeta e integra la libertad.

De igual modo, muchas son las preguntas acerca del dramático término de la Unidad Popular y la muerte de Allende, que no parecen tener convincente respuesta. 
¿Se trató acaso de un Allende en extremo empapado en los valores democráticos que lo hacían, por tanto, depositar excesiva confianza en la consistencia de sus estructuras? ¿Fueron debilidades estratégicas surgidas de una débil o incompleta evaluación de la resistencia política interna y externa hacia la disminución de su poder y riqueza? ¿Hubo insuficiente conocimiento de los fenómenos que ocurrían en el orden económico mundial y también en Chile? ¿Fue exceso de confianza en su gran capacidad y flexibilidad para el manejo de la política interna partidaria y con los opositores? ¿Hubo retraso en la decisión de consultar al pueblo ante la necesidad de abrirse a una alianza más amplia hacia el centro?

Era lo que Allende había decidido hacer a través de un plebiscito. Pero el golpe ya estaba preparado y los golpistas no se lo permitieron. 